
miles south of the signal usually drawn on the maps of
the delta of the Lena. Three days later the expedition
began to erect the building and arrange the instruments.

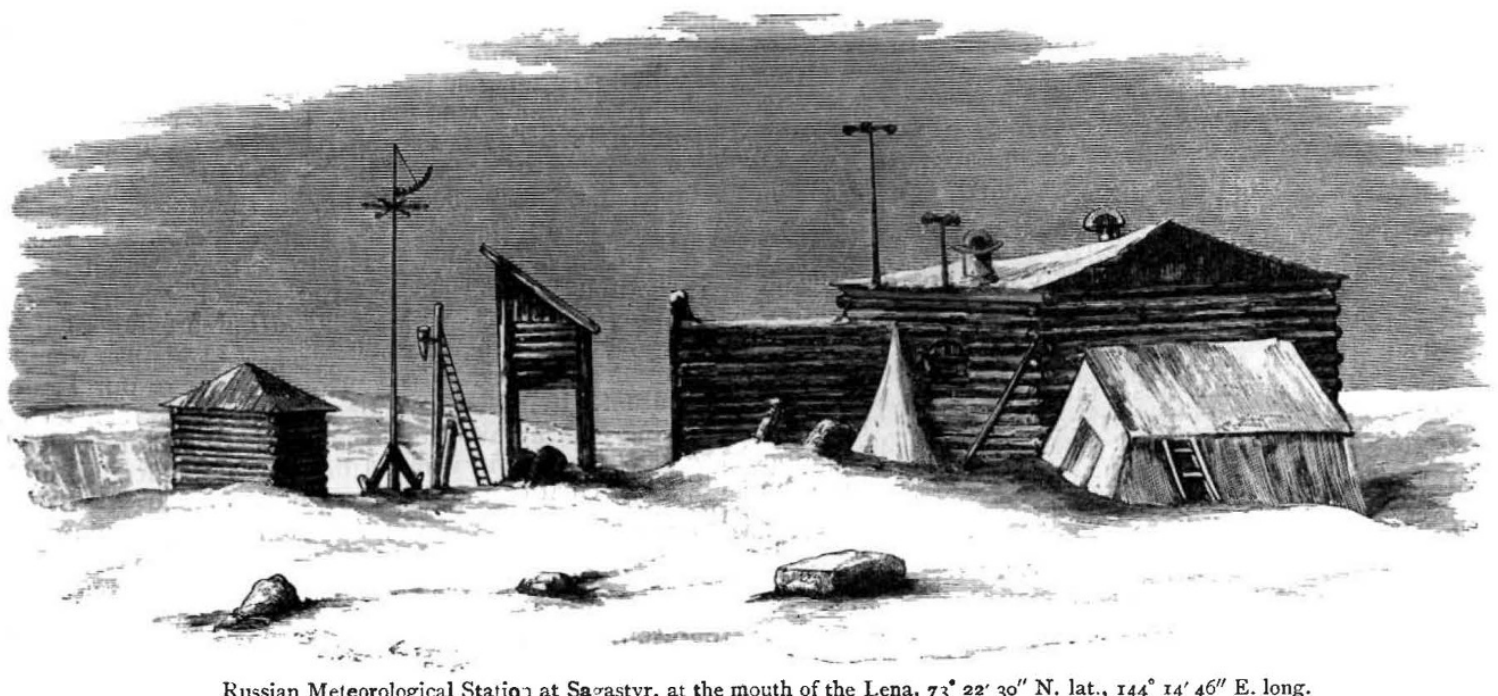

The house of the station is obviously very small; and when looking at Mr. Schütze's sketch of this small building, lost amidst the snow-plain, far from any communica-

\section{THE AURORA BOREALIS}

$\mathrm{A}^{\mathrm{N}}$ MONG the numerous varieties of the aurora borealis or northern light, there is one of particular interest as regards the determination of the origin of this phenomenon. This variety, which was observed and reported upon in 1868 by the members of the Swedish Polar Expedition, takes the form of tiny flames or a phosphorescent luminosity, appearing during the winter months in the Polar regions, around projecting objects, viz. mountain cones and ridges. This phenomenon is so prominent that ore need no: be a scientist to discover it, and it was observed by our well-known philologist, Herr M. A. Castrén, during his journeys in Siberia. Herr Castrén's descriptions of the phenomenon are very minute, and exactly in accordance with its usual appearances, but his observations were, however, not known to me in I868, and it was only on the return of the expedition that I heard of them. The observations made by the Swedish expedition at Spitzbergen led the Finnish Society of Science in I87 I to despatch an expedition, of which I was a member, to Lapland to ascertain if such a phenomenon could not be called forth, or at all events magnified, by mere mechanical appliances. And assuming that the aurora borealis in general, and the variety of the same just mentioned in particular, is caused by electric currents in the atmosphere, an apparatus of the following nature was erected on Luosmavaara, a mountain-top about 520 feet above the surface of the Lake Enare, in Lapland. It consisted of a number of fine points of copper wire laid out in the shape of a wreath two square metres in area, and connected by a circular wire of the same metal. This wreath was attached to a long pole, from the top of which a single copper wire $\left(0^{\circ} 4 \mathrm{~mm}\right.$. in diameter) led to a galvanometer fixed in a room in the Enare vicarage, some two miles distant east, and from the galvanometer another copper wire led to a disk of platina in the earth.

When this circuit was closed, the galvanometer gave a deflexion, although faint. But on the very same night the apparatus was erected, viz. November 22, I871, there atbeared an aurora, which began with a single perpendi- tion with the civilised world, one cannot but admire the devotion of those who have willingly submitted to remain in these inhospitable latitudes for scientific purposes. cular column of light above the top of the Luosmavaara! This column was analysed with the spectroscope, and gave the usual yellow-green line, but whether the column was on or behind the mountain-top could unfortunately not be clearly ascertained. That it, however, had its origin from the apparatus described above appears to me, after the researches were made which I am about to detail, to be beyond a doubt. At the same time, on November 22, 1871, it was observed, when studying the spectrum of the flames which, on that day appeared around the mountain-tops more distinctly than usual, that the characteristic yellow-green line in the spectroscope was returned from nearly every object, as, for instance, the ice of a pond, the roof of a shed, and even, though faintly, from the snow in the immediate vicinity of the observatory. These observations led me to believe that I was within a sphere of electric discharge, whose radius extended considerably around the station.

This interpretation of mine has, however, not been generally accepted by students of the phenomenon, who, on the other hand, have explained the appearance as being an aurora reflected from the earth; but that this theory is erroneous will be clearly demonstrated by the researches detailed below.

In Baron Nordenskjöld's exhaustive investigations of the aurora borealis during the Vega expedition, he states that he was unable to discover this phosphorescent phenomenon which I have observed, and that he had noticed in the spectroscope, in connection with the same, a faint band near the line $\mathrm{D}$; but this has nothing whatever to do with the auroral line. In order, however, to make it clear that I have not confused these two lines, I may state that already in $187 \mathrm{I}$ I observed the absorption-band in question, as will be seen from my work at the time on the aurora borealis and the auroral spectrum. In these researches I determined the wave-length of this line, and as the latter is only apparent in daylight or moonshine, while my observations were without exception made in the dark, it is perfectly clear that this line or band has nothing in common with the auroral one. The two lines are, in fact, of such a different character that they cannot 
be confused for a moment by any one who has had an opportunity of comparing them simultaneously.

During the period which has elapsed since 187I my efforts have been bent on the closest study of the aurora borealis, and an accidental discovery that a Geissler tube may produce certain forms of light without being in direct connection with either pole of an electric battery further stimulated my attention. This led to the result that the electric current emanating from the pole of an electric apparatus, while the other is connected with the earth, can be made to traverse a layer of air of ordinary density without producing any light at all; but when, on the other hand, it encounters a layer of very thin air, the luminous phenomenon will at once appear. These researches led me to construct an auroral apparatus for demonstrating this phenomenon as it appears in nature. The knowledge I have gained of the aurora during my continued labours and the above-mentioned observations in particular, made me conclude that an attempt to produce the auroral phenomenon in the very lap of nature by aiding the action of her own forces, ought to give important results and also originate a method for the future study of the phenomenon. 'In consequence of this idea I made the proposition to the International Polar Congress which I attended at St. Petersburg in I88I, to erect a station at Sodankylä to follow up ny researches, although the results might perhaps be of negative value.

The Experiments on Oratunturi.-For the purpose of carrying out the experiment suggested above, the Finnish Polar Expedition was comparatively well equipped, the Physical Faculty of the University at Helsingfors having contributed instruments as well as wire; but the former had to be slightly altered for the research in view. Circumstances, however, occurred which prevented my work being commenced until the end of November, 1882 ; and after having examined the country and made some preliminary experiments from the steeple of Sodankylä Church, situated close to our observatory, I determined to erect the apparatus on the summit of the Oratunturi Mountain, some twelve miles from the observatory. The top was well suited for the purpose, although surrounded by rising copses of wood, which should, according to theory, be rather detrimental to such experiments. The summit was determined by barometrical measurements to be 1070 feet above the town of Sodankylä. To lead the wire from Oratunturi to Sodankylä was, in consequence of the great distance, impossible, as there were neither wires nor insulators sufficient, and I had therefore to carry out the experiments as follows :-

On the summit of Oratunturi (lat. $67^{\circ} 2 x^{\prime}$, long. $27^{\circ}$ $17^{\prime} \cdot 3$ E. of G.), about 540 metres above sea-level, I laid out the instrument which I have named an "utströmnings" apparatus, i.e. a "discharging" apparatus. It consisted of a bare copper wire $2 \mathrm{~mm}$. in diameter, fitted at every half metre with points soldered thereon. The copper wire was laid out in entwined squares, while the points were raised on poles $2 \frac{1}{2}$ metres high, provided with insulators, so that each inner coil was about $\mathrm{I} 5 \mathrm{~m}$. from the outer one. The apparatus covered a surface area of 900 square metres. From the inner end of this wire an insulated copper wire on poles with telegraph insulators led to the foot of the mountain, where a hut of pine branches was erected; here the wire was connected with a galvanometer, and from this another wire led to a zinc disk in the "earth," i.e. in a flowing spring. The elevation of the apparatus above the zinc disk was i 80 metres, and the direction of the conducting wire from the mountain north-west to south-east.

From the first day the apparatus was finished, viz. December 5 , there appeared almost every night a yellowwhite luminosity around the summit of the mountain, while no such luminosity was seen around any one of the others! The flames were very variable in intensity, and in constant oscillation as those of a liquid fire. Three times it was tested, $2 \frac{1}{2}$ miles off in south-east, by a Wrede spectroscope (small size with two prisms), and it returned a faintly continuous spectrum from $D$ to $F$, in which the auroral line $\lambda=5569$ with soft variable intensity was observed. The galvanometer steadily gave the deflexions of a positive current from the "utströmnings" apparatus to the earth. The deflexion wis so exceedingly variable that the needles were in constant motion when the circuit was closed. A Leclanche's element of ordinary size gave a deflexion which varied according as the positive pole was turned against the mountain or against the earth, but it was always measurable.

It was, however, impossible to continue the observations for any length of time, as hoar-frost quickly developed on the wires and the poles in large quantities, whereby the insulation became affected. The conducting wire from the mountain was of copper insulated with waxed cotton, and $0.8 \mathrm{~mm}$. in diameter. This became so covered with hoar-frost that it broke under the weight in spite of the short distance between the supporting poles, viz. 25 metres. It was, therefore, necessary to examine its entire length before the experiments could be commenced, and as the temperature, as a rule, was under $-30^{\circ} \mathrm{C}$., our work was greatly impeded.

Although the deflexions, by their great variation in the electric current and perhaps, from changes in the electric forces or the imperfect insulation, cannot be of great scientific value, I subjoin them :-

December 13, 1882.- - After several alterations of the galvanometer, and the right sensitiveness having been obtained, the result was, with open circuit: scalereading ${ }^{1}$ of position of equilibrium (a) $36 \mathrm{I}^{\circ} 5$; (b) $362^{\circ} 7$; with closed circuit (c) 457.8 Lor 95.8 parts of the metre $=3.5$, every part of the metre being $2^{\prime} \cdot 2$ ]. This deflexion constantly varied, and often descended to 30 parts of the metre, to rise suddenly again. The temperature was that day comparatively high, viz. $-10^{\circ}$ to $-12^{\circ} \mathrm{C}$. The air was hazy.

December 19, I882.-Plane of equilibrium, $4688^{\circ}$; with closed circuit, $47^{\circ} 6$; deflexion $=3.6$ parts of the metre.

A Leclanche's element placed in the circuit gave-

I. Plane of equilibrium with open circuit $\quad \ldots . \quad \ldots \quad \ldots \quad 469^{\circ} 4$ 2. With the carbon pole against the earth $\ldots . \quad \ldots \quad \ldots \quad 476.4$ 3 . With the carbon pole against the mountain $\quad \ldots \quad \ldots \quad 4679$ Or the current from the atmusphere $=2.75$ parts of the meter. And the current from the element $=4.25 \quad, \quad$, ,

The insulation was here worse than in the previous case, and the temperature very low, viz. $-35^{\circ} \mathrm{C}$.

From December 27 to 29 several experiments were also made, under which the deflexions of the current were greater or less than under the above.

With regard to the construction of the galvanometer it may be mentioned that the instrument consisted of an ordinary wooden frame constructed for the coiling of the wire, while a pair of astatic needles with a mirror could freely swing within the frame thus : one within and the other above the coil. At first the frame was coiled with copper wire $0.5 \mathrm{~mm}$., insulated with indiarubber, but during the experiments this wire was replaced by another $0.4 \mathrm{~mm}$., and insulated with silk inpregnated with stearine. The arrangement of the needles was altered several times, but under the above-recorded experiments they were hung on two fine threads of cocoon silk about $20 \mathrm{~cm}$. long and about $1.5 \mathrm{~mm}$. apart. The deflexions were read with a tube and scale from a distance of 0.8 metre.

The Experiments at Pietarintunturi--On this mountain (lat. $68^{\circ} 32^{\prime} \cdot 5$, long. $27^{\circ} \mathrm{I}^{\prime} \cdot 3$ E. of G.), 950 metres above the sea, a smaller "utströmnings" apparatus was erected in two parts, so that the inner one covered about 80 and the outer 320 square metres. In other respects it

I These figures refer to the reading of a divided metre-scale viewed by reflexion in the mirror of the galvanometer by the "subjective" method through a reading-telescope.-[ED.] 
was similar to the one at Oratunturi, but the galvanometer here was not so sensitive, as the needles had lost some of their astatic quality through the journey.

On December 29 there appeared above this apparatus a single column of aurora some 120 metres in height! Its plane was determined from several points, viz., S.S.W. to E.S.E., within an angle of $90^{\circ}$ with the plane of the horizon, and there was not the slightest doubt of the aurora appearing just above the apparatus. No spectrum analysis was, however, made, as the question of the greatest moment on this occasion was to determine the plane of the column in relation to the apparatus. A faint aurora in the sky at the back of the mountain might perhaps have influenced the analysis; besides which another difficulty arose from the temperature being $-35^{\circ}$, and the instrument in consequence difficult to handle. But that a spectrum similar to the one at Oratunturi and the one of 1871 on the Luosmavaara would have been received I have not the slightest doubt.

The galvanic measurements were effected as follows :First, the galvanometer was connected with the inner coil of the "utströmnings" apparatus, 80 square metres in area, when deflexion was observed; secondly, it was connected with the outer coil, 320 square metres in area; and thirdly, with both apparatuses combined, or 400 square metres in area.

The deflexions were, in consequence of the small sensitiveness of the galvanometer, weak; but it was clearly noticed that the current increased with the area of the apparatus. As the deflexions varied considerably, it was impossible to ascertain exactly their natural law, but it seemed apparent that the strength of the current was proportionate to the surface area of the apparatus laid out. The galvanometer used in this case was similar to the other, but not so sensitive. If I designate the inclinations at Oratunturi with $\mathrm{O}$ and those of Pietarintunturi with $\mathrm{P}$, the relative proportion of the sensitiveness of the galvanometers would be

$$
\mathrm{P}=\mathrm{O} \cdot 370 \text {, }
$$

with very nearly the resistance of 20 Siemens units. The metre was here divided into $I^{\prime} \cdot 2$. The following shows the results of the experiments :-

December 29, I882. - With the inner coil, or an area of 80 square metres :-

$\begin{array}{llll}\text { First deflexion, } & 2 \cdot 1 & \text { parts of the metre. } \\ \text { Second ", } & 0.9 & , & , \\ \text { Third ", } & 1 \cdot 0 & , & , \\ \text { Fourth ", } & 2 \cdot 4 & , & , \\ \text { Fifth ", } & 2 \cdot 0 & ,\end{array}$

The temperature was on that day, as almost during the whole period of experimenting here, $-30^{\circ}$, or under. The air was clear.

December 3I, I882.-With the whole surface of the apparatus, or an area of 400 square metres-

\begin{tabular}{|c|c|c|c|c|}
\hline \multicolumn{2}{|c|}{ First deflexion, } & \multicolumn{3}{|c|}{ I. 6 parts of the metre. } \\
\hline Second & , & 2.8 & , & ," \\
\hline TH & ," & 3.8 & ", & 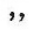 \\
\hline Fou & ," & $3^{\circ} \mathrm{I}$ & ", & ," \\
\hline Fifth & , & $3 \cdot 1$ & , & , \\
\hline
\end{tabular}

With a Leclanchés element the result was :-

I. With the carbon pole against the mountain deflexion $=-0 \cdot 2$ With the zinc , , , , Of which deflexion by the current from the atmosphere $=3.65$ And ,", ," Leclanché's element $=3.85$

2. With the carbon pole against the mountain deflexion $=-\mathrm{I}_{5} \cdot 5$ With the zinc , , , Of which deflexion by the current 'from the atmosphere $=5 \cdot 2$ And ," ", Leclanché's element $=6.7$

The experiments with the different parts of the apparatus resulted as follows :-

I. Plane of equilibrium $\left.\begin{array}{l}(a) 27 \mathrm{I}^{\circ} 6 \\ (b) 27 \mathrm{I}^{\circ} 4\end{array}\right\}=27 \mathrm{I}^{\circ} 5$ open circuit.
Inner apparatus $\mathrm{A}=80$ square metres.

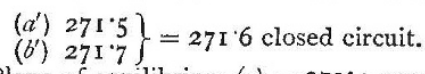

Plane of equilibrium $\langle c\rangle=270^{\circ} 4$ open circuit.

Deflexion from $\mathrm{A}=0.6$.

Outer apparatus $\mathrm{B}=320$ square metres.

(a) Plane of equilibrium $=270 \% 4$ open circuit.

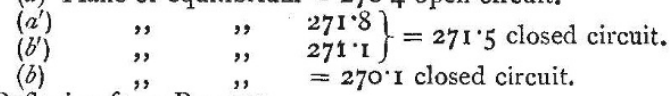

Deflexion from $\mathrm{B}=\ddot{\mathrm{I}} \cdot 2$

Entire apparatus $\mathrm{C}=400$ square metres.

(a) Plane of equilibrium $=270^{\circ} 1$ open circuit.
$\left(a^{\prime}\right)$
$\left(b^{\prime}\right)$
Deflexion for $\mathrm{C}=0$.
$\left.\begin{array}{l}270.9 \\ 270.7\end{array}\right\}=270.8$ closed circuit.

During these experiments it was noticed that the first deflexion was always far greater than the subsequent double, constant ones, and I have therefore noted this one only. When the circuit was closed it was observed that the needle pair always was at rest in the plane of equilibrium.

2. A. Plane of equilibrium $269^{\circ} 7$ open circuit.
$\left(a^{\prime}\right\rangle$
$270^{\circ} 8$ closed circuit,

$\left(a^{\prime}\right) \quad$ " ", $270^{\circ} 8$ closed circuit, Ist defl. $277^{\circ} \mathrm{O}$ (b) " " ", 269.8 open circuit.

Deflexion for $\mathrm{A}=\mathrm{I}{ }^{\circ} \mathrm{O} \quad \ldots \quad \ldots \quad \ldots \quad \ldots \quad \ldots \quad$ Ist defl. $=7 \cdot 2$ B. (a) Plane of equilibrium 269.8 open circuit.

$\left(a^{\prime}\right) \quad, \quad, \quad 27 \mathrm{I}^{\circ} 3$ closed circuit, Ist defl $28 \mathrm{I}^{\circ} \mathrm{O}$ (b) " ", 270.4 open circuit.

Deflexion for $\mathrm{B}=\mathrm{I} \cdot 2 \quad \ldots \quad \ldots \quad \ldots \quad \ldots \quad \ldots$ Ist defl. $=\mathrm{II} \cdot 8$

C. (a) Plane of equilibrium $270^{\circ} 4$ open circuit.

$\left(a^{\prime}\right) \quad, \quad, \quad 27 \mathrm{I} \cdot 8$ closed circuit, Ist defl. $284^{\circ} 9$ (b) $\quad, \quad, \quad, \quad 270^{\circ} 4$ open circuit.

Deflexion for $\mathrm{C}=\mathrm{I}_{4}^{\prime} \quad \ldots \quad \ldots \quad \ldots \quad \ldots \quad \ldots$ xst defl. $=14 \cdot 5$

3. A. (a) Plane of equilibrium 270.4 open cireuit.

(a') " " $27 \mathrm{I}^{\circ} 7$ closed circuit, Ist def. $278 \cdot 2$ (b) " " ", 270.8 open circuit.

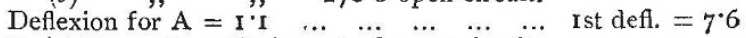

B. (a) Plane of equilibrium 270.8 open circuit.

$\left(a^{\prime}\right) \quad, \quad, \quad 274^{\circ}$ o closed circuit, Ist defl. $282^{\circ} \circ$ (b) " $, ", \quad 273.6$ open circuit.

Deflexion for $\mathrm{B}=\mathrm{I} \cdot 8 \quad \ldots \quad \ldots \quad \ldots \quad \ldots \quad \ldots$ ist defl. $=10.8$

C. (a) Plane of equilibrium $274^{\circ} 5$ open circuit.

(a) " " , $279^{\circ}$ O closed circuit, Ist defl. $292^{\prime} 3$

(b) " ", $275^{\circ} 6$ open circuit.

Deflexion for $\mathrm{C}=3.9 \quad \ldots \quad \ldots \quad \ldots \quad \ldots \quad \ldots$ ist defl. $=17 \cdot 2$

If these observations are connected we obtain :-

$$
\begin{aligned}
& A=80 \text { square metres } \\
& B=320 \quad, \\
& C=400 \quad,
\end{aligned}
$$

Deflexion rst. defl. Deflexion. Ist defl. Deflexion. ist deff.

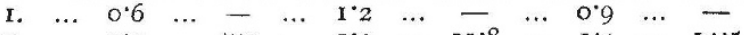
$\begin{array}{lllllllllllll}2 . & \ldots & I^{\circ} \mathrm{O} & \ldots & 7 \cdot 2 & \ldots & \mathbf{I} \cdot 2 & \ldots & \mathbf{I} 1 \cdot 8 & \ldots & \mathbf{I} \cdot 4 & \ldots & \mathbf{1} 4 \cdot 5\end{array}$ $\begin{array}{llllllllllllll}3 . & \ldots & \text { I. } & \ldots & \ldots & 7 \cdot 6 & \ldots & 1.8 & \ldots & \text { 10 } 8 & \ldots & 3 \cdot 9 & \ldots & \text { I } 7 \cdot 2\end{array}$

If it now be considered that the current from the atmosphere was very variable, besides that the insulation was rather imperfect, the results of these experiments are not so reliable as might be desired. Still, this inference can safely be drawn from them, that the strength of the current increases with the area of the "utströmnings" apparatus or with the number of points, but the natural law of the increase I have not yet been able to determine. As will be seen from the subjoined figures the conductive power of the wire was that day very small, although the temperature was comparatively high, viz. at I a.m. $-18^{\circ} \mathrm{C}$, , but falling.

The entire apparatus (C) with one of Leclanchés elements :-

(a) Plane of equilibrium $273 \cdot 1$ open circuit.

$\left(a^{\prime}\right) \quad, \quad, \quad 275^{\circ} 3$ the zinc pole against the mountain.

$\left(b^{\prime}\right) \quad, \quad, \quad, \quad 270 \% 4$ carbon ,

(b) " " ", 270. I closed circuit.

From this we obtain: the current from the atmosphere $=\mathrm{I} \cdot 5$, and from the element $=2 \cdot 45$, which figures show 
the small conducting power of the wire, as well as the weak current from the atmosphere.

Another inference may be drawn from these observations. If we take the average of the results on December $3 I$ on Pietarintunturi, when the whole apparatus was used, it will be 3.2 parts of the metre, and comparing this with that of December 19 on Oratunturi, when the atmospheric conditions were similar, which was 3.6 parts of the metre, and transform these into minutes, the result will be as follows : $3^{\prime} 6$ parts of the metre at $2^{\prime} \cdot 2=7.92 ; 3.2$ parts of the metre at $1^{\prime} \cdot 2=3^{\prime} \cdot 84$, but the sensitiveness of the galvanometer at Pietarintunturi was only 0.36 of that at Oratunturi $=0^{\circ} 37$, and the area of the apparatus in the former 200 square metres against 900 in the latter, and further, assuming that the current increases in proportion to the area of the apparatus, we shall have :

$$
\frac{3^{\prime} \cdot 84}{0.36} \quad \frac{900}{400}=24^{\prime} \cdot 0
$$

And the deflexion $3^{t} 84$ being reduced to the same galvanometer sensitiveness and the same area of apparatus, the actual result is that the experiments at Oratunturi showed a deflexion three times greater than those at Pietarintunturi. The latter place is certainly situated a little higher than the former, but in my opinion the increase of the electric force lies in the fact that Oratunturi is in a higher latitude than Pietarintunturi, i.e. nearer the plane of the aurora borealis. Although the experiments recorded above suffer from inaccuracy on account of the imperfect insulation, I have come to the conclusion that the electric currenl from the atmosphere increases rapidly with the latitude.

The great deflexion which I obtained at Oratunturi on December 13, I882, I do not consider refutes this inference, as the atmospheric conditions on this occasion were exceptional, viz. the temperature high and the air hazy.

The experiments in both places have, however, unfortunately been of a somewhat provisional character, which is due to the external impediments in our way. Thus, when experimenting at Oratunturi, tbe writer had to make a journey in the snow of 20 kilometres, viz.. of four hours' duration, then to examine the apparatus on the summit, clean it from hoar-frost, and often repair it, with the thermometer at $-30^{\circ} \mathrm{C}$. Then only could the experiments be commenced. It was only possible to work for five to eight minutes at a time, as it was necessary to thaw one's benumbed hands before a bonfire lit on the snow. At Pietarintunturi the road was certainly shorter, but, nevertheless, very fatiguing, as it was necessary first to climb a ridge about rooo feet, and then journey about 3 kilometres.

These difficulties, and chiefly the imperfect insulations and the weakness of the wires at my disposal, compelled me to abandon experiments of this character.

SELIM LEMSTRÖM

Professor of the Helsingfors University (To be contimued)

\section{NOTES}

Besides Prof. Huxley the following English men of science have been elected Foreign Associates of the U.S. National Academy of Sciences:--Prof. J. C. Adams, Prof. Cayley, Prof. Sylvester, Prof. Stokes, Sir William Thomson, and Sir J. D. Hooker.

Mr. Herbert Spencer has been elected a Corresponding Member of the Paris Academy of Moral and Political Sciences.

THs remarkable enthusiasm with which the project of the memorial to Charles Darwin was received in Sweden has already been noticed in our columns. The amount of the subscriptions collected, as was said, from all ranks, has just been received by the treasurer of the Darwin Memorial Fund. It is a sum of $382 l$. I $2 s .6 d$., the largest, we believe, that has been contributed by any foreign courtry, and a proof of the zeal on behalf of science that exists in the land of Linnæeus.

WE are glad to learn that America has at length subseribed for a table at the Zoological Station at Naples. In view of the very considerable number of American students in European biological laboratories some surprise has naturally been felt that America has not hitherto been represented at Naples. President Carter and the trustees of Williams College are to be congratulated on having taken the lead in a matter the importance of which must be apparent to all who are interested in the progress of morphological study.

Dr. William Chambers, the head of the eminent publishing firm, well deserves the honour of a baronetey which he has just received, on account of the public services rendered by him to education and to social improvement throughout a long life; he is just the age of the century, we believe.

The public sale of the late Prof. J. Decaisne's library will take place in 1 'aris from June 4 to 23 next. The catalogue of 480 pages, published by Labitte, of Paris, contains more than 5000 entries. classified according to subject by M. Vesque, assistant to the late M. Decaisne. It is probably one of the finest libraries in botany, horticulture, and general natural history which has been sold since the death of Jussieu. The catalogue contains a portrait of Decaisne and a biography by Dr. E. Bornet.

THE death is announced, at the age of seventy-one years, of Mr. James Young of Kellie, the "Sir Paraffin" of his old friend Livingstone. Mr. Young is best known in connection with his process of distillation of paralin oil from bituminous coal, which attained great dimensions, and from which he realised a fortune. Mr. Young took a real and active interest in chemical research, and founded the Chair of Economic Chemistry in Anderson's University, Glasgow ; he was a Fellow of the Royal Society.

THE departure of the Swedish Expedition to Greenland has been postponed to the 22nd, and Baron Nordenskjold will join the Sofia at Gothenburg, instead of coming to Scotland.

\section{A Hygrenic exhibition was opened at Berlin on Saturday.}

THE Society of Arts conversazione will this year be held in the buildings of the International Fisheries Exhibition; the Prince of Wales, the President of the Society, has intimaied his intention of being present. The date is not yet amounced.

IN connection with the recent discussion on the opening of picture galleries and museums on Sundays, the following facts relating to the Whitechapel Fine Art Exhibition are full or interest. This exhibition, which as may not be known to all our readers, is one which is open for thirteen days at Easter in one of the most desolate parts of this great metropolis. It consists of about two hundred pictures of the highest order of merit, which are placed at the disposal of a responsible committee by the artists or those who are fortunate enough to possess them. It is open gratuitously from ten in the morning until ten at night, except on Sundays, when the opening takes place at two o'clock, after morning service. This year, it will be seen from the numbers we give below, that no less than 34,644 of the poorest of the poor visited the pictures; and as fhey were to a very large extent "personally conducted" round the rooms by ladies and. gentlemen who freely gave up their time to the work, the way in which they appreciated the pictures is thoroughly well known. The same men and women came again and again, bringing their friends to show them the pictures in which they themselves had taken the greatest interest. One of the most important points that we wi-h to urge now is, that on the last day the exhibition was open, which 